\title{
OLFACTION AND ESSENTIAL TREMOR
}

\author{
Lucas Barasnevicius Quagliato', Maura Aparecida Viana², \\ Elizabeth Maria Aparecida Barasnevicius Quagliato ${ }^{3}$, Samuel Simis ${ }^{4}$
}

\begin{abstract}
Objective: To characterize the olfactory identification in 40 essential tremor (ET) patients, with the University of Pennsylvania 12 Smell Identification Test (UPSIT), to correlate UPSIT scores to clinical and epidemiological data and to compare it to 89 aged matched controls. Method: Patients were assessed using ET Clinical Scale of Evaluation and UPSIT. Results: In patients with ET, the UPSIT medium score was 9.10, similar to the control group (9.11), which was also observed in all age groups. ET severity did not correlate to UPSIT scores. Conclusion: This study demonstrated normality of olfactory identification on ET, qualifying UPSIT to be an important tool on tremor differential diagnosis of undetermined origin.
\end{abstract}

KEY WORDS: essential tremor, olfaction, UPSIT.

\begin{abstract}
Olfato no tremor essencial
Resumo - Objetivo: Caracterizar a identificação olfatória em 40 pacientes com tremor essencial, através do Teste de Identificação de 12 Cheiros da Universidade de Pensilvânia (TICUP), correlacioná-la aos dados clínicos e epidemiológicos e compará-la com 89 indivíduos normais. Método: Os pacientes foram avaliados com a Escala Clínica de Avaliação do TE e com o TICUP. Resultados: A média de acertos no TICUP nos pacientes com TE foi 9,10, semelhante à do grupo controle (9,11), sendo isso observado em todas as faixas etárias. A gravidade do TE não se correlacionou com o resultado do TICUP. Conclusão: Este estudo demonstrou normalidade da identificação olfatória no TE, qualificando o TICUP como ferramenta importante no diagnóstico diferencial dos tremores de causa indeterminada.
\end{abstract}

PALAVRAS-CHAVE: tremor essencial, olfato, TICUP.

Essential tremor (ET) is the commonest movement disorder and its frequency increases over 40 years. In 1817 James Parkinson denominated ET as a senile tremor, making it different from the disease described on "Assay on Shaking Palsy"'. About 200 years ago, ET was recognized as an isolated symptom, being also described among the youth ${ }^{2}$. ET prevalence increases with age, varying from $0.41 \%^{3}$ to $12.6 \%{ }^{4}$ and familiar incidence from $17 \%$ to $70 \%$, showing traces of autosomal-dominant heritage ${ }^{1,5}$. Little is known about its anatomy and pathophysiology and cerebellum seems to be its plausible generator ${ }^{6,7}$. ET clinical diagnosis proposed by Tremor Research Investigation Group classifies ET as definite, probable or possible ${ }^{8}$. Mild abnormalities of tone or gait are occasionally related to ET, being more severe in advanced phase ${ }^{9,10}$. Several neurological conditions have been associated with central or peripheral olfactory deficits ${ }^{11-13}$. Assessments of different olfactory sorts - identification, threshold, discrimination and memory - have been used on tremor differential diagno- sis. Hyposmia is being considered as an earlier sign of PD and Lewy bodies disease, related to a dopaminergic dysfunction on olfactory tubercles and mesencephalic-piriform cortex pathway ${ }^{14-16}$.

The University of Pennsylvania 12 Smell Identification Test (UPSIT), is a sensible and reproducible tool. A Brazilian research showed a compromising on olfactory identification on PD through UPSIT in $80 \%$ of patients (medium score 5.7 in PD vs 9.1 in controls ${ }^{17}$ ). Researches that used UPSIT described mild abnormalities or normal results on ET and early changes on PD ${ }^{15,18-21}$. The objective of this research was to evaluate the olfactory identification in 40 ET patients, comparing them to 89 controls and correlate UPSIT scores to clinical and epidemiological data.

\section{METHOD}

Forty ET patients from both the outpatient clinic of the Faculty of Medical Sciences from Pontifíce Catholic University of São Paulo, Sorocaba, Brazil and a private clinic from Campinas

Faculty of Medical Sciences from Pontifice Catholic University of São Paulo, Sorocaba SP, Brazil: 'Undergraduated student on Medicine; ${ }^{2}$ MD, Neurologist; ${ }^{3} \mathrm{MD}$, PhD, Neurologist, supported by Scientific Initiation schoolarship (CNPQ); ${ }^{4} \mathrm{MD}$, PhD, Neurologist, Faculty of the Medical Sciences of the State University of Campinas, São Paulo SP, Brazil.

Received 1 July 2008, received in final form 10 November 2008. Accepted 16 December 2008.

Dr. Lucas B. Quagliato - Rua Alfredo Calil 187 - 13101-507 Campinas SP - Brasil. E-mail: lucasquagliato@yahoo.com.br 
were assessed. The design was approved by the Ethical Committee of the Faculty of Medical Sciences from the Pontifice Catholic University of São Paulo.

The control group was the same of the previous research "Olfactory dysfunction in Parkinson's disease"17, in which more 13 subjects (a total of 89 ) were added in order to obtain subjects with the same ages as the patients.

After reading and signing Free and Informed Consent Form, clinical assessment was performed using Essential Tremor Clinic Evaluation Scale (ETCES) that analyses aspects such as intensity, speaking phonation, feeding, hygiene, dressing and working. ETCES scores varies from 0 (without tremor) to 64 (severe tremor)'. Olfactory identification was assessed with UPSIT (a set of 12 odors, that are presented to patients in order to be identified among four options).Control group was assessed using UPSIT.

ET diagnosis was based on Tremor Research Investigation Group $^{8}$, that classifies ET as definite when it is postural, occurring on upper limbs and worsening during action, or it is only postural and it is associated to cephalic tremor. Probable ET is both postural and action tremor of arms, without enhancing during action, or occurs only on it and it can be associated with vocal and head tremor. Possible ET is applied to postural and action tremor on upper limbs, or postural that disappears during action, or isolated tremor on legs, head, neck and tongue

Statistical study was composed by descriptive analysis with dispersion and position measures for continuous variables and frequency tables for categorical variables. Mann-Whitney Test compared continuous or mandatory measures between the two groups and variance analysis with Rank transformation compared three or more groups. When the difference was significant, multiple comparison tests were performed in order to identify the differences. Fisher and chi-square tests were used in order to compare qualitative variables and Spearman coefficient measured the linear association. The significance level adopted was $5 \%$.

\section{RESULTS}

The mean age of ET patients ( 23 females and 17 males) was 59.75 years (SD 19.16; from 22 to 92 years) and out of the 89 subjects on the control group ( 55 females and 34 males) was 56.08 years (SD 15.65; from 22 to 79 years)

Mean ages of ET onset and disease history time were 42.33 years (SD 24.49; from 1 to 80 years) and 17.35 years (SD 14.59; from 1 to 48 years) respectively. The mean ETCES score was 16.23 (SD 14.55; from 1 to 54).

Twenty one patients (52.5\%) were diagnosed as having definite ET, 11 (27.50\%) as possible and $8(20 \%)$ as probable ET. The mean UPSIT score in patients with ET was 9.11 (SD 1.3; from 6 to 12) and in the control group was 9.10 (SD 1.55; from 6 to 12). The UPSIT score description is showed on Table 1.

Mean UPSIT score from 22 to 50 years was 9.18 (SD 1.54; from 9 to 12) on ET patients and 9.43 (SD 0.99; from 8 to 11) on the control group ( $p=0.5036)$. Among the elderly patients (71-92 years), the mean score was also similar, being 8.50 (SD 1.51; from 6 to 11) on ET and 8.93 (SD 1.44; from 6 to 12) on the control group.

Correlating UPSIT score to gender, it was observed similar ET scores between females and males, being respectively 9.26 (SD 1.51; from 6 to 12) and 8.88 (SD 1.62; from 7 to 12). On the control group the mean UPSIT scores were 9.20 (SD 1.34; from 6 to 12) among the women and 8.97 (SD 1.24; from 7 to 11) in men.

Smoking incidence was $7.5 \%$ on ET group compared to $10.1 \%$ on the controls. Table 2 shows the smoking and nonsmoking UPSIT scores in both groups.

ET group showed the same score frequency as the control group on the identification of each of the 12 odors. Only the second odor (turpentine) showed a low score level in both groups (20\% on ET and $10 \%$ on control group) (Figure).

Cephalic tremor was observed in 8 patients (20\%), 39 (97.5\%) showed upper right limb tremor, 37 (92.5\%) on upper left limb, 4 (10\%) on lower right limb and 5 (12.5\%) on lower left limb.

Tandem gait abnormalities were observed in three patients (7.5\%) and cognitive deficit in just one (2.5\%). It was reported by $21 \mathrm{ET}$ patients (52.5\%) an improvement with

Table 1. UPSIT scores distribution between the two groups and ages.

\begin{tabular}{lcccccc}
\hline Group & Age & $\mathrm{n}$ & Mean & SD & Minimum & Maximum \\
\hline Controls & $22-30$ & 10 & 9.60 & 0.70 & 8.00 & 10.00 \\
& $31-40$ & 3 & 10.00 & 1.73 & 8.00 & 11.00 \\
& $41-50$ & 10 & 9.10 & 0.99 & 8.00 & 11.00 \\
& $51-60$ & 27 & 9.00 & 1.62 & 6.00 & 11.00 \\
& $61-70$ & 25 & 9.04 & 1.10 & 7.00 & 11.00 \\
Essential tremor & $71-92$ & 14 & 8.93 & 1.44 & 6.00 & 12.00 \\
& $22-30$ & 6 & 9.17 & 1.33 & 8.00 & 11.00 \\
& $41-50$ & 5 & 9.20 & 1.92 & 7.00 & 12.00 \\
& $51-60$ & 4 & 10.50 & 0.58 & 10.00 & 11.00 \\
& $61-70$ & 13 & 9.15 & 1.63 & 6.00 & 12.00 \\
& $71-92$ & 12 & 8.50 & 1.51 & 6.00 & 11.00 \\
\hline
\end{tabular}


Table 2. Smoke and UPSIT scores.

\begin{tabular}{lccccc}
\hline Group & $\mathrm{n}$ & Mean & SD & Minimun & Maximum \\
\hline Controls & $\mathrm{NS}$ & 80 & 9.15 & 1.33 & 12.00 \\
& $\mathrm{~S}$ & 9 & 8.78 & 0.97 & 10.00 \\
Essential tremor & $\mathrm{NS}$ & 37 & 9.11 & 1.56 & 12.00 \\
& $\mathrm{~S}$ & 3 & 9.00 & 1.73 & 10.00 \\
\hline
\end{tabular}

NS, non smoker; S, smoker.

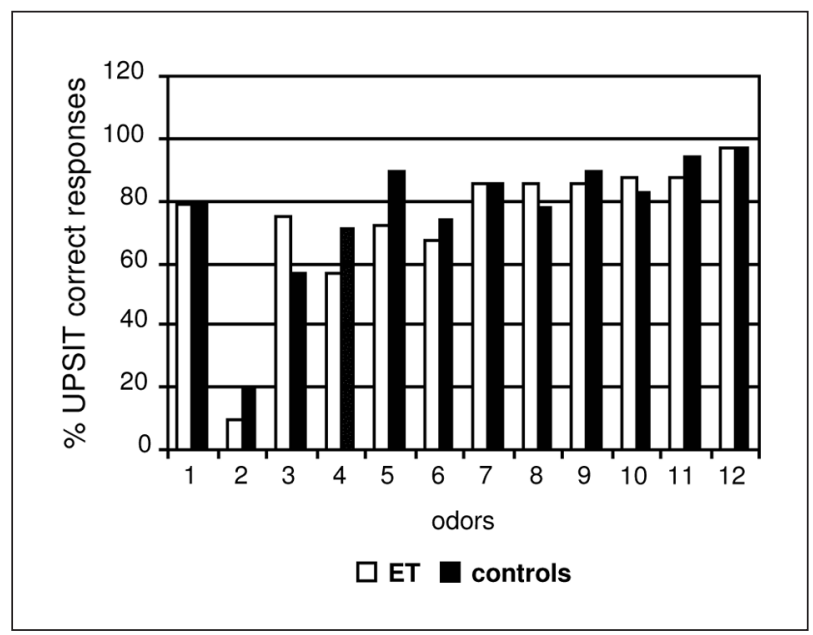

Figure. Frequency of correct responses in each UPSIT odor.

the use of medications to treat the condition, although 7 (17.5\%) did not show any improvement and $12(30 \%)$ had never taken any medicines. Six (25\%) patients received primidone, $14(58.33 \%)$ propranolol and $2(8.3 \%)$ received an association of both. Two patients (8.33\%) referred improvement with alcohol beverage intake.

Thirty three patients (82.5\%) referred ET family history, of which $60.61 \%$ fulfilled definite ET criteria diagnosis. The seven patients without ET family history showed in their majority $(71.43 \%)$ a possible ET diagnosis $(\mathrm{p}=0.0087)$.

Patients with and without family history of ET referred $51.52 \%$ and $57.14 \%$ of improvement with treatment respectively $(p=1.0000)$. There was no difference between patients with and without family history of ET in relation to tremor localization or tandem gait abnormalities.

The mean age of disease onset in patients with $\mathrm{fa}$ milial ET was 38.52 years (SD 25.06; from 1 to 80 ) and for the ones without family history was 60.29 years (SD 9.60; from 45 to 71$)(p=0.0298)$.

Mean ETCES and UPSIT scores on patients with family history of ET were 16.42 (SD 14.31; from 1 to 54) and 8.94 (SD 1.54; from 6 to 12), and on patients without family history were 15.29 (SD 16.78; from 4 to 52) and 9.86 (SD 1.46; from 8 to 12) respectively.

There was no correlation among patients current age, age of ET onset and response to medications for ET treat- ment. UPSIT scores did not correlated to ETCES, neither to tandem gait abnormalities. Patients with tandem gait abnormalities showed higher total ETCES scores (40.67; SD 21.39; from 16 to 54 ) and mean age of 70 years (SD 4.36; from 65 to 73 ).

There was no correlation among ET history time, ETCES and UPSIT scores. Mean disease history time for definite ET patients was 22.29 years (SD 14.05; from 1 to 46 ), significantly higher than possible ET patients (7.64 years; $S D=10.77$, from 2 to 35 ) and probable ET (17.75 years; $S D=15.29$, from 2 to 48$) ;(p=0.0061)$.

\section{DISCUSSION}

ET is an isolated clinical manifestation, diagnosed incidentally or when the patient comes to neurological assessment because of functional and social impairments generated by tremor. The onset age does not predict both evolution and therapeutic response'. It has been suggested that ET is a syndrome, occasionally associated with cognitive disturbances and balance abnormalities, possibly related to cerebellar dysfunction'.

On this casuistics, mean ETCES score of ET patients was 16.23 , classifying them as having moderate impairment. The mean age of disease onset was 17 years, long enough to classify $80 \%$ of the patients in definite or possible diagnosis.

ET patients were similar to controls in relation to UPSIT scores, with a medium score of 9.1 correct answers. There was no difference between those two groups in relation to gender and age, neither among the identification of each one of the 12 odors. The clinical impairment, evaluated by ETCES, did not correlate to UPSIT scores. Those results are agreeable to researches that evaluated olfactory identification in $\mathrm{ET}^{15,18,20}$ and it was not found, in this ET group, the mild abnormalities reported by Louis and co-workers ${ }^{19,21}$. These authors tested 37 ET patients with a 40 identification odor set and reported mild changes on olfactory discrimination, being that ET patients showed a medium score of 29 and controls of 31.9. There has been no correlation in this study among the disease duration, its severity and olfactory dysfunction. The same authors, after increasing the number of patients studied, concluded that olfactory dysfunction is mild on ET, which could be related to cerebellar dysfunction, as observed on ataxias ${ }^{21}$.

Like UPSIT, olfactory event-related potentials were indistinguishable from controls when the effects of age of onset, gender and smoking were taken into account, as reported by Shah et al. ${ }^{22}$.

As reported in a previous Brazilian research ${ }^{17}$, the second UPSIT odor - turpentine - was seldom recognized by controls, and will be excluded in further studies. On 
this paper ${ }^{17}, 80 \%$ of PD patients presented abnormal olfactory identification, showing a medium UPSIT score of 5.7. PD patients showed, in opposite to ET patients, more difficulty to recognize all UPSIT odors if compared to controls. The olfactory identification assessment is, therefore, a sensible tool to the differential diagnosis of PD.

Smoking did not compromised odor identification accuracy in both ET patients and controls, but the low number of tobacconists $10.1 \%$ in the control group and $7.5 \%$ of ET patients) does not permit definite conclusions about tobacco influence on this olfactory modality.

According to the literature ${ }^{1,8}$, tremor localization predominated on upper limbs. Mild abnormalities of tone or gait are occasionally related to $\mathrm{ET}$, being more severe in advanced phase. Singer et al. described that half of the patients had tandem gait abnormalities, as compared to $28 \%$ of age-matched controls ${ }^{9,10}$. The three patients in this study that presented abnormal tandem gait were older, so this alteration could reflect other associated conditions.

Propranolol or primidone improved both tremor symptoms in $52.2 \%$ of the patients and alcoholic beverages improved in $8.33 \%$ and according to the literature, this therapeutic response was seen in $50 \%$ to $70 \%$ of ET patients'. Regarding to the age of patients, neither the present age nor the age at ET onset, did not correlate to the therapeutic response.

ET patients presented high familial incidence of ET (82.5\%), according to previous publications ${ }^{4,23}$. Patients with familial ET did not disagree from others in relation to the therapeutic response to propranolol/primidone, ETCES scores, tremor localization, abnormal tandem gait and medium UPSIT scores.

In more than $50 \%$ of familial ET patients, the onset symptoms start up to 40 years of age and all patients presented them before 65 . Sporadic cases tend to initiate later in life'. ET initiated earlier in those patients with familial history ( $38 \mathrm{vs} 60$ years of age), as already published $1^{1,4}$. There was no difference between the patients with or without familial ET in relation to ETCES and UPSIT scores, unlike the results found by Shah et al. ${ }^{23}$, that described better UPSIT performances in patients with familial form.

Rest tremor could be an isolated sign in ET patients and the olfactory analysis, demonstrating that UPSIT scores are significantly lower on PD than ET patients, made this differential diagnosis possible ${ }^{20}$.

We conclude that UPSIT scores demonstrated normality in olfactory identification in this group of ET patients, contributing to this method to a differential diagnosis of unknown origin tremor.

\section{REFERENCES}

1. Cersosimo MG, Koller WC. Essential tremor. 2.Ed. In: Watts RL, Koller WC (eds). Movement disorders. New York: Mc-Graw-Hill 2004:431-458.

2. Critchley M. Observations on essential (heredofamilial) tremor. Brain 1949;72:113-139.

3. Haerer AF, Anderson DW, Schoenberg BS. Prevalence of essential tremor: results from the Copiah County Study. Arch Neurol 1982;39:550-551.

4. Rautakorpi I, Takala J, Marttila RJ, Sievers K, Rinne UK Essential tremor in a Finnish population. Acta Neurol Scand 1982;66:58-67.

5. Tanner CM, Goldman SM, Lyons KE, et al. Essential tremor in twins: an assesment of genetic vs environmental determinants of ethiology. Neurology 2001;57:1389-1391.

6. Pascual-Leone A, Valla-Sole J, Toro C, et al. Resetting of essential tremor and postural tremor in Parkinson's disease with transcranial magnetic stimulation. Muscle Nerve 1994;17:800-807.

7. Elbe R. Essential tremor frequency decreased with time. Neurology 2000;55:1547-1551.

8. Findley LJ, Koller WC, DeWitt P, et al. In: Lord Walton of Detchant (ed). Classification and definition of tremor. In Indications for and clinical implications of botulinum toxin therapy. London: Royal Sociedty of Medicine 1993:22-23.

9. Singer C, Sanchez-Ramos J, Weiner WJ. Gait abnormality in essential tremor. Mov Disord 1994:9:193-196.

10. Stolze H, Petersen G, Raethjen J, et al. The gait disorder of advanced essential tremor. Brain 2001:124:2278-2286.

11. Pahwa R, Koller WC. Is there a relationship between Parkinson's disease and essential tremor?Clin Neuropharmacol 1993;16:30-35.

12. Hawkes C. Olfaction in neurodegenerative disorder. Mov Disord 2003;18:364-372.

13. Muller A, Mungersdorf M, Reichmann H, Strehle G, Hummel T. Olfactory function in Parkinsonian syndromes. J Clin Neurosci 2002;9:521-524.

14. Katzenschlager R, Lees AJ. Olfaction and Parkinson's syndromes: its role in differential diagnosis. Curr Opin Neurol 2004;17:417-423.

15. Liberini P, Parola S, Spano PF, Antonini L. Olfaction in Parkinson's disease: methods of assessment and clinical relevance. J Neurol 2000;247: $88-96$.

16. Berendse HW, Ponsen MM.Detection of preclinical Parkinson's disease along the olfactory trac(t). J Neural Transm 2006(Suppl):S321-S325.

17. Quagliato LB, Viana MA, Quagliato EMAB, Simis S. Olfactory dysfunction in Parkinson's disease. Arq Neuropsiquiatr 2007;65:657-652

18. Busenbark KL, Huber SJ, Greer G, Pahwa R, Koller WC. Olfactory function in essential tremor. Neurology 1992;42:1631-1632.

19. Louis ED, Bromley SM, Jurewicz EC, Watner D. Olfactory dysfunction in essential tremor: a deficit unrelated to disease duration or severity. Neurology 2002;59:1631-1633.

20. Louis ED, Jurewicz EC. Olfaction in essential tremor patients with and without isolated rest tremor. Mov Disord 2003;18:1387-1389.

21. Applegate LM, Louis ED. Essential tremor: mild olfactory dysfunction in a cerebellar disorder. Parkinsonism Relat Disord 2005;11:399-402.

22. Shah M, Muhammed H, Findley LJ, Hawkes CH. Olfactory test in the diagnosis of essential tremor. Parkinsonism Relat Disord 2008(3); Epub ahead of print.

23. Rajput AH, Offord KP, Beard CM, Kurland LT. Essential tremor in Rochester, Minnesota: a 45-year study. J Neurol Neurosurg Psychiatry 1984; 47:466-470. 